\title{
UniverUSAL: la universidad inclusiva
}

\author{
José Ángel Gallego González; José Lorenzo García Sánchez; \\ Rocío Galache Iglesias; Víctor Tejedor Hernández
}

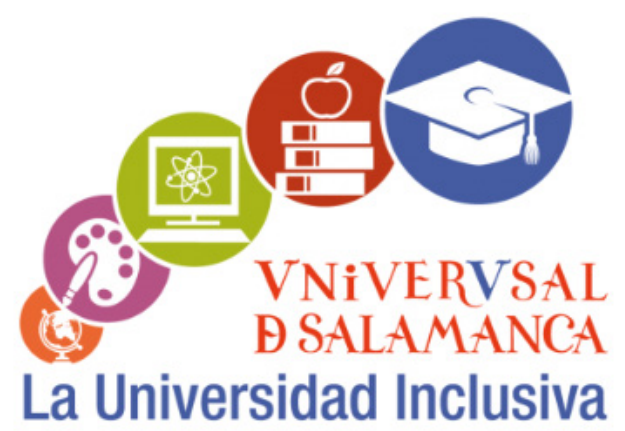

$\mathrm{H}$

ISTÓRICAMENTE, LAS PERSONAS CON DISCAPACIDAD han tenido importantes dificultades para acceder a la Universidad. Por este motivo, la Universidad de Salamanca, en colaboración con el Ayuntamiento, la Diputación de Salamanca y la Mesa de Promoción de la Salud, ha creado e impulsado el programa UniverUSAL: la universidad inclusiva.

Este proyecto promueve la creación de una universidad inclusiva, con un formato accesible que pretende acercar los estudios universitarios a las personas con discapacidad intelectual y/o con problemas de salud mental.

El Proyecto se dirige a una treintena de participantes que disfrutan de una experiencia de inmersión en la comunidad universitaria y en los servicios que la Universidad de Salamanca pone a su disposición.

El alumnado se divide en dos grupos en función de las necesidades de apoyo de los participantes:

1. Un primer grupo compuesto por aquellos participantes con discapacidad intelectual con mayores necesidades de apoyo, a los que se les facilita un transporte adaptado y acompañamiento de personal de apoyo. 
2. Un segundo grupo compuesto por personas con un mayor nivel de autonomía (problemas de salud mental y discapacidad intelectual con menores necesidades de apoyo).

Los objetivos que se persiguen son:

- Acercar a las personas con discapacidad intelectual y problemas de salud mental a la cultura y la ciencia como vehículos de transmisión de experiencias y conocimientos.

- Promover la plena participación en el espacio de educación superior que ofrece la universidad a las personas que no podrían acceder por las vías oficiales previstas.

- Hacer de la Universidad de Salamanca un espacio plena-

Los participantes son la razón principal de la existencia del proyecto.

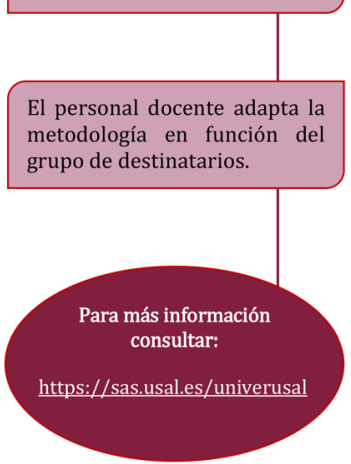
mente inclusivo y de apoyo a la diversidad.

UniverUSAL consta de dos cursos académicos con materias troncales obligatorias, seminarios y talleres prácticos mensuales en formato de clases participativas.

La formación la imparte profesorado universitario en horario de tarde y con grupos reducidos.

Las conclusiones trasladadas por el equipo de trabajo que conforma el programa UniverUSAL destacan el impacto social causado en el ámbito universitario, institucional y asociativo de la ciudad de Salamanca, debido en gran medida a la colaboración entre los distintos agentes sociales y a la gran implicación de los participantes en el proyecto.

El proyecto se organiza en torno a dos cursos. En el primer curso se imparten dos módulos: Ciencias de la vida y Grandes obras y autores. En el segundo curso, los módulos impartidos son: Cultura general y Medioambiente.

El programa UniverUSAL se divulgó por distintos medios como son las propias entidades colaboradoras (Ayuntamiento, Diputación y las Fundaciones: Ariadna, ASPACE, Asperger, ASPRODES, Down Salamanca, Salud Mental Salamanca - AFEMC, AFIM, Insolamis y ASPAR - La Besana).

También se divulgó gracias a los medios de comunicación de la propia Universidad de Salamanca y externos como la prensa escrita, radio y redes sociales. 